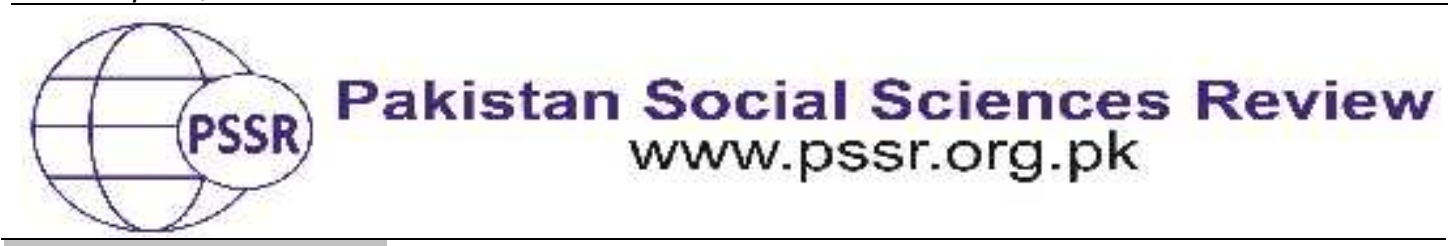

RESEARCH PAPER

\title{
The Importance of IPIP Five Factor Personality Traits in Prediction of University Students' Emotional Intelligence
}

\author{
Dr. Rafaquat Ali* 1 Dr. Syed Kaleem Ullah Shah Bukhari 2 \\ Sher Muhammad ${ }^{3}$
}

1. Assistant Professor, Department of Education, Bahawalnagar Campus, Bahawalnagar, The Islamia University of Bahawalpur, Punjab, Pakistan

2. Assistant Professor, Department of Educational Training, Bahawalnagar Campus, Bahawalnagar, The Islamia University of Bahawalpur, Punjab, Pakistan

3. Assistant Professor, Faculty of Social Sciences and Humanites, Hamdard University Karachi, Islamabad Campus Islamabad, Pakistan

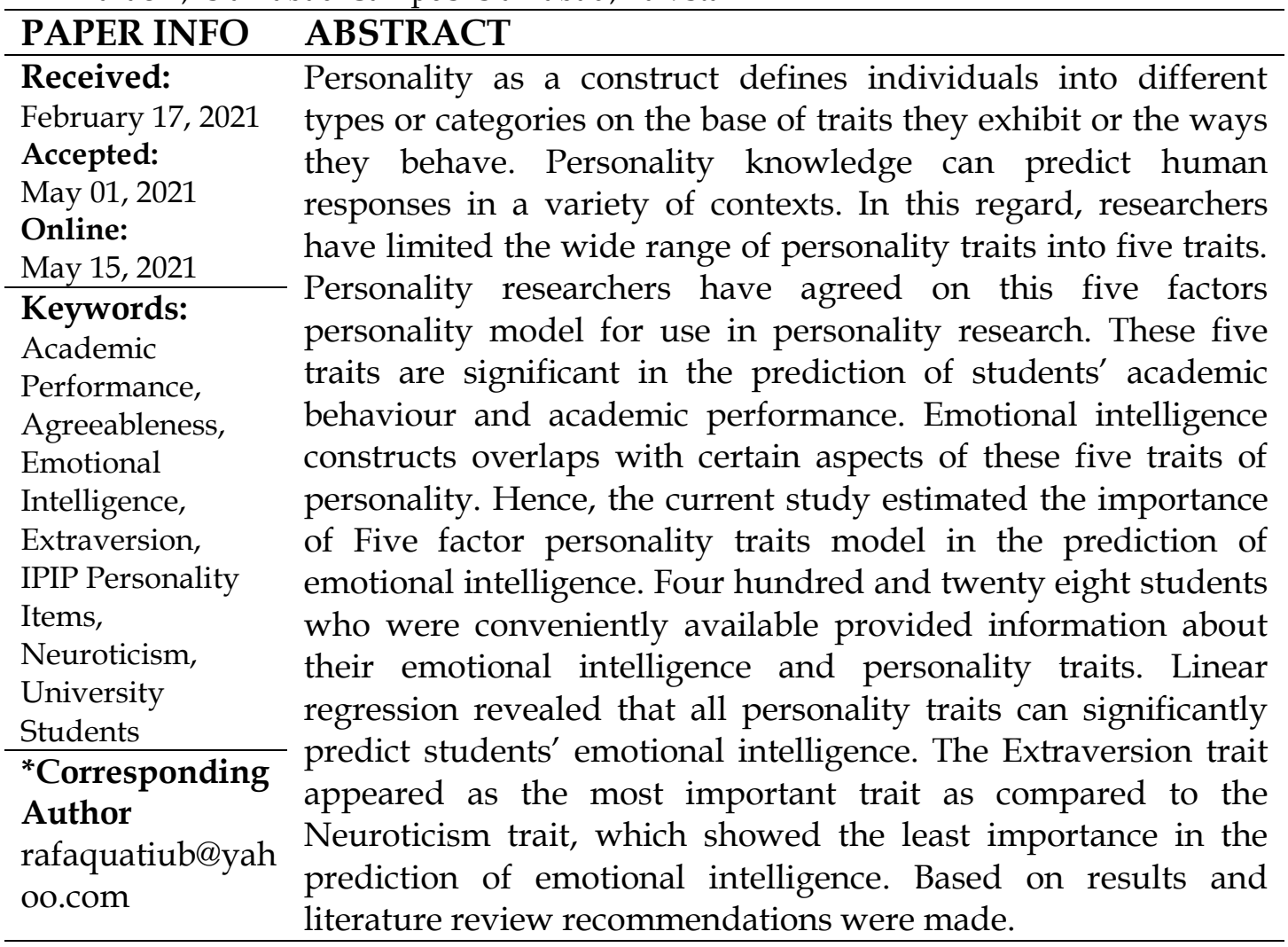

\section{Introduction}

The human quest is to identify and comprehend stable explicit differences in humans resides in human instinct. Therefore, individuals identify routine human responses to different social, emotional and cognitive stimuli and label them to distinct traits and categories. The drives for these distinct labelling are; to describe themselves and others in routine life and to predict human behaviour (Chamorro- 
Premuzic \& Furnham, 2005b). In this way, the concept of human personality is developed. Accordingly, personality consists distinctive stable traits that force an individual to behave in specific and more or less consistent way (ChamorroPremuzic \& Furnham, 2005b).

In human history, philosophers and academicians have proposed different theories and models to study the personality. As a result, there was a plethora of disjointed, and disintegrated personality theories that lack empirical evidence (John et al., 2008). In that chaotic state of affairs in personality research, there were diverse rating scales, alternative terms for different personality traits, or even for similar personality traits (McCrae \& Costa, 2008). However, that problem has been resolved in recent years and academicians have almost agreed that there are five basic factors or traits of human personality (Crozier, 1997). The Five factor model of personality has appeared as the most agreed model to understand the personality of humans (Chamorro-Premuzic \& Furnham, 2005c). This five factor model has engrossed all traits of human personality into five universal traits and enabled personality researchers to use this integrated systematic model to measure and explain the construct of personality (McCrae \& Costa, 2008). This consensus to reduce different personality traits into five basic traits was a breakthrough and a milestone in history of personality research (Crozier, 1997). Nowadays, researchers can use standardised vocabulary, terms and concepts of personality (John et al., 2008).

In five factors personality approach, the personality construct is broken down into five traits namely; Openness, Agreeableness, Conscientiousness, Neuroticism and Extraversion (Chamorro-Premuzic \& Furnham, 2005c). Maltby et al. (2017) described these traits in operational form. According to them, Openness means that a person has intellectual curiosity, is able to think many perspectives of an issue or problem, accepts new ideas, imagine actively and welcomes new experiences. The high scorers are usually independent thinkers. The Agreeableness trait measures how well an individual is trusting, helpful and sympathetic. It measures the positive social interactions with others in the society. The conscientiousness factor specifies that someone is disciplined and able to regulate his or her life activities. He/she plans events in life, and remain focused on the plan and targets. The Neuroticism factor is related to emotional stability. High scorers in this trait are usually emotionally unstable, volatile and unpredictable in their emotional expressions. On the other hand, extraversion trait estimates an individuals' sociability. It measures the social, friendly, and optimistic traits. The opposite of extravert is introvert. Introvert people are unfriendly and unsocial.

The Five factors model of personality has performed as an important predictor of human development and learning at schools. The Ericson's psychosocial development theory comprises eight stages of psychosocial developed across human life span, and this theory has predicted the development of five factors of personality (Zhang, 2013). Furthermore, it is evident in recent studies that personality plays an important role in learning at educational institutions. The impact of personality on 
school achievements can be in two ways: direct impact and indirect impact. Although, cognitive intelligence is an important predictor of students' performance at schools. However, the predictor role of cognitive intelligence decreases with progression from primary schooling to university education, as compared to personality traits whose predictor power increases along with this progression (Chamorro-Premuzic \& Furnham, 2005d). For the reason, intelligence predicts what an individual can do, whereas personality traits define what an individual is likely to do. Therefore, personality construct acts as a more convincing tool for the prediction of students' future achievements, behaviours and knowledge required to be successful at schools (Chamorro-Premuzic \& Furnham, 2005d).

There are certain factors and constructs that directly impact students' academic achievements, such as regulation of learning (Pintrich \& Zusho, 2007; Zimmerman, 1990), learning strategies, learning patterns (Vermunt \& Vermetten, 2004), and learning approaches (Biggs, 1987). However, personality literature affirms that these constructs are strongly associated with certain traits of five factors personality construct. The strategies of self-regulation of learning are associated with five personality traits. For example, help seeking is associated with extroversion trait, time management, and effort regulation are associated with Agreeableness, metacognition, effort regulation, time management, elaboration strategies and critical thinking are linked with conscientiousness (Bidjerano \& Dai, 2007). However, the Intellect trait is associated to almost all strategies of self-regulation of learning (Bidjerano \& Dai, 2007). Furthermore, students' personality traits are associated with the use of elaboration, and organisation learning strategies or the use of memorization strategies. Students' conscientiousness trait of personality is associated with rehearsal and regulation strategies, whereas openness to experience trait can predict the use of elaboration strategies (Blickle, 1996).

Based on students' cognitive processing strategies, regulation of learning, learning motives and conceptions of learning, Vermunt and Vermetten (2004) theorised four learning patterns; meaning directed, application directed, reproduction directed and undirected learning patterns. These patterns are also found to be related to students' personality traits (Busato et al., 1998). By integration of students' learning strategies, and intentions to read textbook knowledge, Biggs (1987) proposed three learning approaches: the surface, deep and achieving learning approaches. There is an evidence that openness to experience personality trait has direct positive relationship with deep learning approach (Chamorro-Premuzic \& Furnham, 2008).

Apart from indirect impacts of personality traits on students' academic achievements, these have direct impacts on students' academic performance. The Neuroticism personality trait has negative impact on students' academic performance (Homayouni, 2011). Likewise, Openness to experience trait has positive impact on students' academic performance as compared to the Extraversion trait that sometimes do not have positive impact on students' academic performance ( $\mathrm{O}^{\prime}$ Connor \& Paunonen, 2007). Both Agreeableness and conscientiousness traits have 
positive connections with educational outcomes (Bidjerano \& Dai, 2007; Busato et al., 2000). However, most of the times, the relationships between personality traits and academic attainments are mediated by learning strategies (Blickle, 1996) and learning approaches (Chamorro-Premuzic \& Furnham, 2009).

From above discussion, it is clear that personality traits are better predictors of students' academic accomplishments because these personality traits can also predict all important predictors of students' performance at schools. Nowadays, alternative approaches of intelligence such as emotional and social intelligence are in focus because there are doubts about the role of general intelligence in success in routine life situations and at schools (Chamorro-Premuzic \& Furnham, 2005a). Emotional intelligence is the measure of human ability to recognise, regulate and use of his/her and others' emotions in different contexts (Barrett \& Salovey, 2002). Furthermore, it can provide the foundations of social intelligence (Salovey \& Mayer, 1990). Therefore, it is the most important among alternative intelligence approaches. However, this alternative approach to intelligence appears to be overlapping with items of the big five factors of personality. In this way, these forms of intelligence appear to be a subsection of personality (Chamorro-Premuzic \& Furnham, 2005b). Though, items of different personality traits and some emotional intelligence measures overlap (Avsec et al., 2009), but the purpose to asses is different in both (Chamorro-Premuzic \& Furnham, 2005b).

Emotional intelligence has positive impacts on students' self-regulation of learning (Mabekoje, 2010), and self-efficacy (Wen et al., 2020). Likewise, emotional intelligence directly impact students' academic performance (Akram et al., 2016). It can also define students' drives and perseverance to learn different task at school (Afolabi et al., 2009). Moreover, academicians have questioned students' social and emotional learnings at schools (Keefer et al., 2018). These reasons demand further investigations about relationships of emotional intelligence with different factors important in pedagogical, social and personal contexts.

\section{Hypothesis}

The above discussion underlines the importance of the personality and emotional intelligence in students learning at schools. However, there requires an understanding of their interrelationships. Hence, this study answers the research question that how different traits of five factors personality model predict university students' emotional intelligence? This study examined the hypothesis that different traits of five factors personality model can significantly predict students' emotional intelligence. Therefore following was the null hypothesis of this study:

- University students' personality traits will not significantly predict their emotional intelligence. 


\section{Material and Methods}

The researchers used survey research approach and convenience sampling (Gay et al., 2012) in this study. The sample consisted students from different departments of the Islamia University of Bahawalpur. Due to Covid19 pandemic, it was not safe and possible to manually collect data from students through printed questionnaires. Therefore, data were collected online. As a result of it, 428 students' online responses were selected for data analysis. The online questionnaire interface consisted information about students' demographic backgrounds, personality and emotional intelligence. The personality section of the online questionnaire consisted 60 items. These 60 items represent 15 subscales of five personality traits. These items were selected from the International Personality Item Pool website. These items measured five traits of personality. Each personality trait has further three sub-trait measures of personality (Table 1). The emotional intelligence section of this online questionnaire consisted 33 items taken from a uni-dimensional measure of Schutte et al. (1998).

Table 1

Sub-scale in Five Factor Traits

\begin{tabular}{cccc}
\hline Personality Trait & \multicolumn{2}{c}{ Personality Traits } & Subscales \\
\hline Conscientiousness & Cautiousness & $\begin{array}{c}\text { Self- } \\
\text { discipline }\end{array}$ & Achievement Striving \\
\hline Agreeableness & Trust & Altruism & Sympathy \\
\hline Neuroticism & Depression & Anxiety & Anger \\
\hline Extraversion & Assertiveness & Friendliness & Excitement Seeking \\
\hline Openness & Emotionality & Intellect & Artistic Interests \\
\hline
\end{tabular}

Source : Johnson (2014)

SPSS software was used in data analysis. The chosen statistical test to test the hypothesis was linear regression. The five personality types were independent variables, whereas, emotional intelligence was the depended variable.

\section{Results and Discussion}

The relationships of different personality traits with emotional intelligence are displayed in Table 2. All personality traits except Neuroticism have significant correlation with emotional intelligence. Among different personality traits, the agreeableness trait has the highest significant correlation with emotional intelligence. Whereas, the Conscientiousness personality trait has the lowest significant relationship with emotional intelligence. Although, the correlation of the Neuroticism trait and emotional intelligence is negative but it is insignificant.

Table 2

Personality Traits and Emotional Intelligence Correlations

\begin{tabular}{ccc}
\hline Personality Traits & Emotional Intelligence & Significance \\
\hline Neuroticism & -.048 & .162 \\
\hline
\end{tabular}




\begin{tabular}{cll}
\hline Extraversion & .401 & .000 \\
\hline Openness & .371 & .000 \\
\hline Agreeableness & .433 & .000 \\
\hline Conscientiousness & .310 & .000 \\
\hline
\end{tabular}

Table 3 and Table 4 show statistics about model fit and the null hypothesis. The statistics in Table 3 and Table 4 show that regression null hypothesis, “University students' personality traits will not significantly predict their emotional intelligence" is rejected $(\mathrm{F}(5,422)=45.515, \mathrm{p}=0.0000)$. It is evident from Table No. 03 and Table No. 04 that different personality traits significantly explained 34.3 percent variance in students' emotional intelligence. The value of adjusted $\mathrm{R}^{2}$ indicates that it is good model fit.

Table 3

Model Summary

\begin{tabular}{ccccc}
\hline Model & R & R Square & Adjusted R Square & Std. Error of the Estimate \\
\hline 1 & $0.592^{\mathrm{a}}$ & 0.350 & 0.343 & 12.95009 \\
\hline
\end{tabular}

a. Predictors: (Constant), Conscientiousness, Extraversion, Agreeableness, Neuroticism, Openness

b. Dependent variable: Emotional Intelligence

Table 4

Regression Model ANOVA ${ }^{a}$ Table

\begin{tabular}{ccccccc}
\hline & Model & $\begin{array}{c}\text { Sum of } \\
\text { Squares }\end{array}$ & df & $\begin{array}{c}\text { Mean } \\
\text { Square }\end{array}$ & F & Sig. \\
\hline \multirow{4}{*}{1} & Regression & 38165.230 & 5 & 7633.046 & 45.515 & 0.000 \\
& Residual & 70771.425 & 422 & 167.705 & & \\
& Total & 108936.654 & 427 & & & \\
\hline
\end{tabular}

a. Dependent Variable: Emotional Intelligence

b. Predictors: (Constant), Conscientiousness, Extraversion, Agreeableness,

Neuroticism, Openness

The Table 5 shows that the beta slope values of all independent variables included in this regression model are significant. The beta value (regression slope) of the constant is significant $(17.769, \mathrm{p}=0.031)$. The values of regression slopes of different personality traits and emotional intelligence are significant; Neuroticism (0.212, $p=0.031)$, Extraversion (0.860, $p=0.000)$, Openness (0.347, $p=0.003)$, Agreeableness $(0.530, p=0.000)$, Conscientiousness $(0.626, p=0.000)$. The statistics of Table No. 05 shows that the least important personality trait in the prediction of emotional intelligence is Neuroticism. One unit increase in Neuroticism scores cause only an increase of 0.212 units in emotional intelligence. On the other hand, the most important personality trait in the prediction of emotional intelligence is Extraversion. One unit increase in extraversion scores cause 0.860 units increase in emotional intelligence. It is obvious from Table No. 05 that all personality traits significantly 
predict emotional intelligence, although their contribution to cause a change in emotional intelligence varies.

Table 5

Coefficient Table

\begin{tabular}{|c|c|c|c|c|c|c|}
\hline & \multirow[t]{2}{*}{ Model } & \multicolumn{2}{|c|}{$\begin{array}{l}\text { Unstandardized } \\
\text { Coefficients }\end{array}$} & \multirow{2}{*}{$\begin{array}{c}\begin{array}{c}\text { Standardized } \\
\text { Coefficients }\end{array} \\
\text { Beta } \\
\end{array}$} & \multirow[t]{2}{*}{$\mathbf{t}$} & \multirow[t]{2}{*}{ Sig. } \\
\hline & & B & Std. Error & & & \\
\hline \multirow{6}{*}{1} & (Constant) & 17.769 & 8.226 & & 2.160 & .031 \\
\hline & Neuroticism & .212 & .098 & .099 & 2.165 & .031 \\
\hline & Extraversion & .860 & .117 & .310 & 7.383 & .000 \\
\hline & Openness & .347 & .116 & .140 & 2.988 & .003 \\
\hline & Agreeableness & .530 & .106 & .224 & 5.002 & .000 \\
\hline & Conscientiousness & .626 & .117 & .263 & 5.357 & .000 \\
\hline
\end{tabular}

Dependent variable: Emotional Intelligence

The regression equation derived from above Table No. 05 to calculate students' emotional intelligence is as below:

$$
E I=a+b_{\mathrm{N}} X_{\mathrm{N}}+b_{\mathrm{E}} X_{E}+b_{\mathrm{O}} X_{0}+b_{\mathrm{A}} X_{\mathrm{A}}+b_{\mathrm{C}} X_{\mathrm{C}}
$$

$E I=$ Emotional intelligence

$a=$ constant

$b_{\mathrm{N}}$ Beta slope Neuroticism personality trait

$b_{E}=$ Beta slope Extraversion personality trait

$b_{O}=$ Beta slope Openness personality trait

$b_{A}=$ Beta slope Agreeableness personality trait

$b_{C}=$ Beta slope Conscientiousness personality trait

$X$ means the scores in the relevant personality trait: $X_{N}=$ Neuroticism Score, $X_{E}=$ Extraversion scores, $X_{0}=$ Openness Score, $X_{A}=$ Agreeableness Score, $X_{C}=$ Conscientious Score.

The students' emotional intelligence can be calculated by putting relevant beta values and scores of personality traits in the model equation. If the students' score is 01 in each personality trait, then the students' emotional intelligence on scale used in this study will be:

$$
\begin{gathered}
E I=a+b_{\mathrm{N}} X_{\mathrm{N}}+b_{\mathrm{E}} X_{E}+b_{\mathrm{O}} X_{0}+b_{\mathrm{A}} X_{\mathrm{A}}+b_{\mathrm{C}} X_{\mathrm{C}} \\
E I=17.769+0.212(1)+0.860(1)+0.347(1)+0.530(1)+0.626(1)
\end{gathered}
$$




$$
E I=17.769+0.212+0.860+0,347+0.530+0.626
$$

$$
E I=20.344
$$

Based on above model parameters, the calculated importance of different personality traits in the prediction of emotional intelligence is displayed in Figure 1. The Extraversion personality trait is most important player in the prediction of students' emotional intelligence. Whereas, the role of the Neuroticism personality trait is the least important in the prediction of students' emotional intelligence in this study.

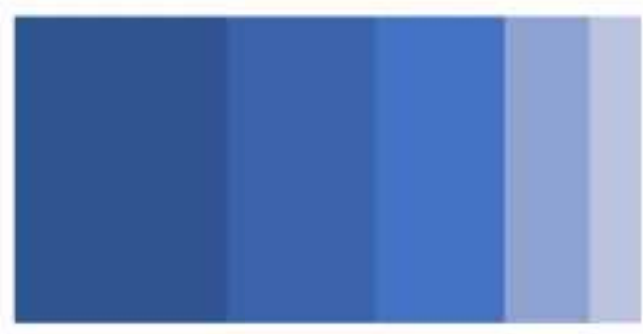

Extraversion

Conscientiousness

- Agreeableress

Operness

Neuroticism

Figure 1: Predictor Importance of Different Personality Traits

\section{Discussion}

The results of this study indicate that it is possible to predict students' emotional intelligence from their personality scores. The prediction of emotional intelligence by personality traits is understandable because most of the measures used in both constructs overlap (Avsec et al., 2009). The correlation co-efficient shows that Neuroticism is negatively associated with emotional intelligence. In prediction of emotional intelligence, there is a minimum role of Neuroticism. It is a measure of emotional stability and higher scores of Neuroticism means emotional instability and unpredictability (Maltby et al., 2017). The moderate relationships among five personality traits and emotional intelligence are compatible with the contemporary literature (Andrei et al., 2015). The most important role of Extraversion trait in prediction of emotional intelligence is matching with findings of other studies (Avsec et al., 2009; Dehghanan et al., 2014; van der Zee et al., 2002).

The second most important predictor in this study in prediction of emotional intelligence is conscientiousness trait. There is inconclusive literature about the second most important predictor in prediction of emotional intelligence. Avsec et al. (2009) found Conscientiousness, whereas, Alghamdi et al. (2017), Dehghanan et al. (2014) found Agreeableness, and van der Zee et al. (2002) found Emotional stability/Neuroticism as the second most important predictor of emotional intelligence. However the difference in the impact of conscientiousness and 
agreeableness on emotional intelligence is smaller in this study. The different findings about personality traits and their importance in prediction of emotional intelligence in different studies may be because of different underlying facets of personality traits, different measures of emotional intelligence and different populations.

This study confirmed the point of view of personality researchers. Personality researchers argue that although, different facets and subscales of personality traits overlap with emotional intelligence measures, and personality traits and emotional intelligence constructs look similar, but both are used and theorised for different purposes (Chamorro-Premuzic \& Furnham, 2005b). Neuroticism personality trait and measures of emotional intelligence have almost similar scales. But there is no significant relationship between these two factors in this study and the prediction role of Neuroticism in prediction of emotional intelligence is minimum. It is understandable because Neuroticism trait describes what person usually is likely to do but emotional intelligence measures what it is (Chamorro-Premuzic \& Furnham, 2005b). Most of the times, individuals avoid to express what they are rather they do what is socially acceptable.

The relationships of different personality traits with emotional intelligence revealed in this study are different forms in relationship of different personality traits with students' academic performance and academic achievements. The personality traits significantly related to success in academic tasks at schools are different from the personality traits related significantly with emotional intelligence. For example, Chamorro-Premuzic and Furnham (2005d), and Busato et al. (2000) found conscientiousness trait as the most important personality trait that impacts students' academic achievements. However extraversion trait is the most important trait in prediction of emotional intelligence (Avsec et al., 2009; Dehghanan et al., 2014; van der Zee et al., 2002). Nonetheless, there is an evidence that predictor importance of different personality traits in academic achievements depend on nature of subjects (Homayouni, 2011) and educational levels (Chamorro-Premuzic \& Furnham, 2005d).

Likewise, the personality traits associated with regulation of learning are conscientiousness and openness to experience (Blickle, 1996). Furthermore, openness to experience is associated with learning approaches (Chamorro-Premuzic \& Furnham, 2008). In this way, personality traits strongly associated with regulation of learning and learning approaches are different than those significantly associated with emotional intelligence.

It seems from findings of this study that emotional intelligence has different nature than the nature of attributes required for success in examinations. The relationships of different personality traits to different intelligence measures and academic achievements depend on the underlying dimensions or facets of personality traits. These underlying facets sometimes become more important in impacting the personality traits relationships with other factors ( $\mathrm{O}^{\prime}$ Connor \& Paunonen, 2007). 
Although, Neuroticism trait is least important predictor in prediction of emotional intelligence. However, it has negative impact on students' academic achievement and positive association with undirected learning patterns (Busato et al., 1998). Among five factors of personality, the negative impact of Neuroticism on students' learning is well acknowledged (O'Connor \& Paunonen, 2007). Therefore, students with high Neuroticism scores can have emotional and learning problems.

\section{Recommendations}

Students' personality traits should be examined while treating their academic problems at educational institutions because these traits may help us to choose suitable frameworks to help emotionally disturb and academically suffering students. Researchers should use other personality trait facts not explored in this study while examining the relationships between personality traits and emotional intelligence. 


\section{References}

Afolabi, O. A., Ogunmwonyi, E., \& Okediji, A. (2009). Influence of emotional intelligence and need for achievement on interpersonal relations and academic achievement of undergraduates. Educational research quarterly. 33(2), 60-72.

Akram, S., Masome, M., \& Davood, A. (2016). The relationship between emotional intelligence and academic achievement in English language among secondary school students in Tehran. International Journal of Humanities and Cultural Studies (Special Issue), 444-455.

Alghamdi, N. G., Aslam, M., \& Khan, K. (2017). Personality Traits as Predictor of Emotional Intelligence among the University Teachers as Advisors. Education Research International. 2017, 9282565.

Andrei, F., Mancini, G., Mazzoni, E., Russo, P. M., \& Baldaro, B. (2015). Social status and its link with personality dimensions, trait emotional intelligence, and scholastic achievement in children and early adolescents. Learning and Individual Differences. 42, 97-105.

Avsec, A., Takšić, V., \& Mohorić, T. (2009). The Relationship of Trait Emotional Intelligence with the Big Five in Croatian and Slovene University Student Samples. Psihološka obzorja / Horizons of Psychology. 18(3), 99-110.

Barrett, L. F., \& Salovey, P. (2002). Introduction. In L. F. Barrett \& P. Salovey (Eds.), The wisdom in feeling : psychological processes in emotional intelligence (pp. 1-10). London: The Guilford Press.

Bidjerano, T., \& Dai, D. Y. (2007). The relationship between the big-five model of personality and self-regulated learning strategies. Learning and Individual Differences. 17(1), 69-81.

Biggs, J. B. (1987). student Approaches to Learning and Studying, Resaerch Monograph. Hawthorn: Australian Council of Educational Research.

Blickle, G. (1996). Personality traits, learning stratigies, and performance. European Journal of Personality. 10(5), 337-352.

Busato, V. V., Prins, F. J., Elshout, J. J., \& Hamaker, C. (1998). The relation between learning styles, the Big Five personality traits and achievement motivation in higher education. Personality and Individual Differences. 26(1), 129-140.

Busato, V. V., Prins, F. J., Elshout, J. J., \& Hamaker, C. (2000). Intellectual ability, learning style, personality, achievement motivation and academic success of psychology students in higher education. Personality and Individual Differences. 29(6), 1057-1068. 
Chamorro-Premuzic, T., \& Furnham, A. (2005a). Intellectual Ability. In T. ChamorroPremuzic \& A. Furnham (Eds.), Personality and Intellectual Competence. New Jersey: Lawrence Erlbaum Associates, Inc.

Chamorro-Premuzic, T., \& Furnham, A. (2005b). Overview: Predicting Future Achievements. In T. Chamorro-Premuzic \& A. Furnham (Eds.), Personality and Intellectual Competence. New Jersey: Lawrence Erlbaum Associates, Inc.

Chamorro-Premuzic, T., \& Furnham, A. (2005c). Personality Traits. In T. ChamorroPremuzic \& A. Furnham (Eds.), Personality and Intellectual Competence. New Jersey: Lawrence Erlbaum Associates, Inc.

Chamorro-Premuzic, T., \& Furnham, A. (2005d). Predictors of Academic and Work Performance. In T. Chamorro-Premuzic \& A. Furnham (Eds.), Personality and Intellectual Competence. New Jersey: Lawrence Erlbaum Associates, Inc.

Chamorro-Premuzic, T., \& Furnham, A. (2008). Personality, intelligence and approaches to learning as predictors of academic performance. Personality and Individual Differences. 44(7), 1596-1603.

Chamorro-Premuzic, T., \& Furnham, A. (2009). Mainly Openness: The relationship between the Big Five personality traits and learning approaches. Learning and Individual Differences. 19(4), 524-529.

Crozier, W. R. (1997). The reality of personality. In Individual Learners Personality Differences in Education. London: Routledge.

Dehghanan, H., Abdollahi, H., \& Rezaei, M. (2014). A study on effect of big five personality traits on emotional intelligence. Management Science Letters. 4(6), 1279-1284.

Gay, L. R., E., M. G., \& Airasian, P. (2012). In C. Robb (Ed.), Educational research : competencies for analysis and applications (10th ed.). New Jersey: Pearson Education.

Homayouni, A. (2011). Personality Traits And Emotional Intelligence As Predictors Of Learning English And Math. Procedia - Social and Behavioral Sciences. 30, 839843.

John, O. P., Naumann, L. P., \& Soto, C. J. (2008). Paradigm Shift to the Integrative Big Five Trait Taxonomy History, Measurement, and Conceptual Issues. In O. P. John, R. W. Robins \& L. A. Pervin (Eds.), Handbook of personality: Theory and research (Third ed., pp. 114-158). New York: Guilford Press. 
Johnson, J. A. (2014). Measuring thirty facets of the Five Factor Model with a 120item public domain inventory: Development of the IPIP-NEO-120. Journal of Research in Personality. 51, 78-89.

Keefer, K. V., Parker, J. D. A., \& Saklofske, D. H. (2018). Three Decades of Emotional Intelligence Research: Perennial Issues, Emerging Trends, and Lessons Learned in Education: Introduction to Emotional Intelligence in Education. In K. V. Keefer, J. D. A. Parker \& D. H. Saklofske (Eds.), Emotional Intelligence in Education (pp. 1-22). Switzerland: The Springer.

Mabekoje, S. (2010). Emotional Intelligence and Self-Regulation among School-Going Adolescents: Self-Efficacy as a Mediator. Contemporary Humanities. 4, 209-222.

Maltby, J., Day, L., \& Macaskill, A. (2017). Personality Theory in Context. In M. John, D. Liz \& M. Ann (Eds.), Personality, individual differences and intelligence (Fourth Edition ed.). United Kingdom: Pearson Education.

McCrae, R. R., \& Costa, P. T. (2008). The Five-F actor Theory of Personality. In O. P. John, R. W. Robins \& L. A. Pervin (Eds.), Handbook of personality: Theory and research (Third ed., pp. 159-181). New York: Guilford Press.

O'Connor, M. C., \& Paunonen, S. V. (2007). Big Five personality predictors of postsecondary academic performance. Personality and Individual Differences. 43(5), 971990.

Pintrich, P., R, \& Zusho, A. (2007). Student Motivation and Self-Regulated Learning in the College Classroom. In R. Perry \& J. Smart (Eds.), The Scholarship of Teaching and Learning in Higher Education: An Evidence-Based Perspective (pp. 731-810). Netherlands: Springer

Salovey, P., \& Mayer, J. D. (1990). Emotional Intelligence. Imagination, Cognition and Personality. 9(3), 185-211.

Schutte, N. S., Malouff, J. M., Hall, L. E., Haggerty, D. J., Cooper, J. T., Golden, C. J., et al. (1998). Development and validation of a measure of emotional intelligence. Personality and Individual Differences. 25(2), 167-177.

van der Zee, K., Thijs, M., \& Schakel, L. (2002). The relationship of emotional intelligence with academic intelligence and the big five. European Journal of Personality. 16, 103-125.

Vermunt, J., \& Vermetten, Y. (2004). Patterns in Student Learning: Relationships Between Learning Strategies, Conceptions of Learning, and Learning Orientations. Educational Psychology Review. 16(4), 359-384. 
Wen, Y., Chen, H., Pang, L., \& Gu, X. (2020). The Relationship between Emotional Intelligence and Entrepreneurial Self-Efficacy of Chinese Vocational College Students. International Journal of Environmental Research and Public Health. 17, 4511.

Zhang, L. f. (2013). Psychosocial development and the big five personality traits among Chinese university students. Learning and Individual Differences. 23(0), 163167.

Zimmerman, B. (1990). Self-regulating academic learning and achievement: The emergence of a social cognitive perspective. Educational Psychology Review. 2(2), 173-201. 